\title{
BIOFICÇÃO EM QUERIDO DIEGO, TE ABRAZA QUIELA (1985), DE ELENA PONIATOWSKA: UMA LEITURA ENLUTADA
}

\section{BIOFICTION IN QUERIDO DIEGO, TE ABRAZA QUIELA (1985), BY ELENA PONIATOWSKA: A BEREAVED READING}

\author{
Dênis Moura de QUADROS ${ }^{1}$ \\ Antônio Carlos MOUSQUER ${ }^{2}$
}

\begin{abstract}
Resumo: A bioficção (BOLAÑOS, 2017) (re)escreve a biografia de figuras esquecidas e silenciadas pela História, o pouco que conseguimos encontrar sobre elas sendo escasso demais para reconstruir registros dessa natureza. Para tal finalidade, a ficção serve como base. Assim, propomos neste artigo uma leitura, pelo viés do luto, de Querido Diego, te abraza Quiela (1985), em que Elena Poniatowska resgata e reconta uma pequena parte da biografia da artista plástica Angelina Beloff (1879-1969?), descolando sua vida do epíteto de "primeira esposa de Diego Rivera".
\end{abstract}

Palavras-chave: Bioficção. Biografia. Vidas imaginárias. Luto. Angelina Beloff.

\begin{abstract}
Biofiction (BOLAÑOS, 2017) (re)writes the biography of figures forgotten and silenced by History and about which the little we can find is insufficient to reconstruct records of this type, for such purpose, fiction serves as the basis. Therefore, we propose a reading under the bereavement point of view of Querido Diego, te abraza Quiela (1985) in which Elena Poniatowska recovers and recounts a small part of the biography of the plastic artist Angelina Beloff (1879-1969?), taking her life off the epithet of "Diego Rivera's first wife".
\end{abstract}

Keywords: Biofiction. Biography. Imaginary lives. Bereavement. Angelina Beloff.

\section{Considerações iniciais}

O criador de bioficções busca a (re)criação de um ser verossímil, segundo o conceito aristotélico, e essa verossimilhança não se preocupa com uma possível ou certa veracidade dos fatos que se contam, ou seja, é ficção. O biógrafo ficcional trabalha nos espaços em branco, nos silêncios das histórias, nos rasgos, elencando figuras que merecem/precisam ser reavaliadas historicamente. Elena Poniatowska (1932- ) é a biógrafa ficcional que reavalia a biografia da artista plástica Angelina Beloff (1879-1969?), conhecida historicamente como uma das esposas do também artista plástico Diego Rivera (1886-1957). O presente artigo pretende analisar a obra Querido Diego, te abraza Quiela (1985) sob a perspectiva do trabalho de luto. Para tanto,

\footnotetext{
${ }^{1}$ Doutorando em Letras, área de concentração História da Literatura pela Universidade Federal do Rio Grande FURG; bolsista CAPES. denis-dp10@ hotmail.com

${ }^{2}$ Professor Associado da Universidade Federal do Rio Grande. Doutorado em Linguística e Letras pela Pontifícia Universidade Católica do Rio Grande do Sul e pós-doutorado pela Université Sorbonne Nouvelle Paris 3 (bolsista CAPES).acmousquer@yahoo.com.br
} 
elencamos como arcabouço teórico o ensaio metapsicológico Luto e melancolia (1996), de Sigmund Freud (1856-1939), e os escritos do casal austríaco Nicolas Abraham (1919-1975) e Maria Törok (1925-1998) em A casca e o núcleo (1995). Além disso, servem-nos de base os estudos lacanianos acerca do fantasma $(1985 ; 2008)$, o luto sob a perspectiva de um ato, de um sacrifício de "um pedaço de si" (ALLOUCH, 2011) e como ato sociopolítico (BUTLER, 2006). Há ainda o psicólogo Juan-David Nasio (1942- ), que compreende o trabalho de luto freudiano como um processo de coexistência, de simbolização do objeto faltoso e nos faz refletir sobre esse trabalho (NASIO, 2005).

A vida de Angelina Beloff traz muitos rasgos, muitos espaços em branco e esquecimentos. O pouco que sabemos dela gira em torno de seu casamento conturbado com Diego Rivera, que a abandona em Paris para retornar ao México. Ana Paula Guerrero Olavarrieta, no artigo Angelina Beloff como misionera cultural: una revolución de su arte (2017), afirma que o primeiro ponto para compreendermos a importância da obra de Beloff no México é descolar sua figura do epíteto que a ronda, qual fantasma, de "esposa de Diego Rivera". Esse descolamento nos permite pensar que a viagem de Beloff ao México não gira em torno de uma possível busca da figura de Diego, mas, sim, de uma relação que ela estabelecera com o México e com a cultura mexicana, ou seja, a construção de uma identidade cultural. A perspectiva de leitura é que o objeto faltoso não é a figura de Diego Rivera, mas o que ele representa simbolicamente: a identidade cultural de Beloff.

Sigo a perspectiva de Guerrero Olavarrieta (2017): “(...) resolver os vazios que existem em torno da obra e a falta de informação que (...) não se encontram ao alcance do público" (GUERRERO OLAVARRIETA, 2017, p. 190, tradução nossa) ${ }^{3}$. Para tanto, a bioficção de Poniatowska nos leva a refletir sobre esse recorte da vida de Angelina Beloff, esse biografema (BARTHES, 1979) em que ela, comumente retratada como frágil e dependente da figura de Rivera, "renasce", passando pelo trabalho de luto. Para tanto, a bioficção nos serve como suporte para compreender esse processo, visto que, seguindo a perspectiva de compreensão de Aimée González Bolaños (2016, p. 156-157), também:

(...) assumo a identidade da biografia imaginária como ficcional, transgressiva tanto do modelo biográfico diacrônico da historiografia moderna quanto das versões da história oficial. Se o sujeito não é mais uma entidade estável, coerente e grande parte da história se descompacta em micro-histórias tão ambíguas, duvidosas e instáveis como o próprio sujeito, cada biografia pode ser uma virtualidade inexplorada,

\footnotetext{
${ }^{3}$ No original: “(...) resolver los vacios que hay en torno a la obra y la falta de información que (...) no se encuentran al alcance del publico” (GUERRERO OLAVARRIETA, 2017, p. 190).
} 
especulação do que foi desde a perspectiva do que pode ter sido (BOLAÑOS, 2016, p. 156-157, tradução nossa). ${ }^{4}$

Querido Diego, te abraza Quiela (1985) traz doze cartas de Quiela ${ }^{5}$ destinadas a Diego Rivera. As cartas datam do período compreendido entre 19 de outubro de 1921 a 22 de julho de 1922, o que equivale a uma gestação normal humana que totaliza uma média de quarenta semanas. Além disso, são doze cartas, número cíclico que representa, também, os doze meses de um ano que, por si, marca uma volta inteira do planeta Terra sobre si mesmo. Ainda, o número 12 é resgatado nos mitos judaico-cristãos como os 12 apóstolos de Jesus Cristo e a representação da perfeição permanente na kabbalah ${ }^{6}$ que representam as 12 tribos de Israel. As primeiras sete cartas são datadas do ano de 1921 e as outras cinco do ano de 1922; da primeira até a penúltima há um período de tempo entre elas de, em média, 15 dias, sendo a primeira datada no mês de outubro, a segunda e a terceira no mês de novembro, da quarta à sétima no mês de dezembro, da oitava à décima no mês de janeiro, a décima primeira no mês de fevereiro e a última no mês de julho que marca o fim do ciclo de trabalho de luto. Esse fim do ciclo, aqui lido como trabalho de luto, se dá quando Quiela toma consciência do fim, da ruptura e, como nos concebe Allouch (2011) sacrifica esse "pedaço de si” ou, ainda, segundo Nasio (2005) consegue simbolizar a perda encontrando subterfúgios para suplantá-la que é a construção de sua identidade cultural mexicana.

\section{Uma leitura enlutada de Quiela}

Ao falarmos de luto, o ensaio metapsicológico de Sigmund Freud é a base para todo o estudo posterior acerca de luto e melancolia; sendo assim, não poderia deixar de retornar a ele. Freud (1996) compreende que: “O luto, de modo geral, é a reação à perda de um ente querido, à perda de alguma abstração que ocupou o lugar (...) como o país, a liberdade ou o ideal de alguém, e assim por diante" (FREUD, 1996, p. 249). Além disso, esse processo que leva ao que Freud chama de "trabalho de luto" presume que, após um tempo não determinado, a perda seja

\footnotetext{
${ }^{4}$ No original: “(...) asumo la identidad de la biografía imaginaria como ficcional, transgressiva tanto del modelo biográfico diacrónico de la historiografía moderna como de las versiones de la historia oficial. Si el sujeto no es más una entidad estable, coherente y gran historia se descompone en microhistorias tan ambiguas, dudosas y instables como el propio sujeto, cada biografía puede ser una virtualidad inexplorada, especulación de lo que fue desde la perspectiva de lo que pudo haber sido" (BOLAÑOS, 2016, p. 156-157).

${ }^{5}$ Diminutivo utilizado por Diego Rivera para se referir a Angelina Beloff, sua primeira esposa.

${ }^{6}$ Palavra de origem hebraica que significa, etimologicamente, recepção, designando um sistema religiosofilosófico que investiga a natureza divina e suas faces, é também uma das mais antigas vertentes do judaísmo.
} 
superada. Essa superação é lida por muitos como a substituição do objeto faltoso por outro que recebe toda a carga libidinal que o objeto possuía. Esta também é a leitura de Judith Butler (2006), fato em que ele não compreende como pode haver essa substituição. Butler então compreende que o trabalho de luto é sociopolítico e está pautado na perda dos laços que nos ligam ao objeto faltoso que, por si, nos servem de (auto)referência.

\begin{abstract}
Quando perdemos alguns destes laços que nos constituem, não sabemos quem somos nem o que fazer. Em um nível, descubro que te perdi "a ti” somente para descobrir que "eu” também desapareço. Em outro nível, talvez o que perdi "em" ti, isso para o que não tenho palavras, seja uma relação não constituída exclusivamente nem por mim nem por ti, contudo que vai a ser concebida como o laço pelo que estes términos se diferenciam e se relacionam (BUTLER, 2006, p. 48, tradução nossa). ${ }^{7}$
\end{abstract}

Essa perda opera na ruptura desses laços que, quase sempre, ocorrem de maneira abrupta, contudo, o corte abrupto abre uma espécie de "ferida" que infecciona e demora tempo demais para começar a cicatrizar e mesmo cicatrizada deixa rastros. São nesses rastros que Butler pensa ser o luto e seu trabalho, pois mesmo passado um tempo, esse objeto faltoso não deixa de reverberar na memória de quem o perdeu, ou seja, ele não pode ser substituído. Na obra, Quiela recorda em mais de uma carta a morte de Dieguito, filho dela com Diego Rivera, que acaba falecendo por complicações respiratórias em um inverno rigoroso em Paris. Percebemos que ela encerra esse luto através do que Freud chama de trabalho, mas o filho não é esquecido ou substituído, os rastros da ferida seguem intactos.

Juan-David Nasio (2007), seguindo a leitura de Butler, compreende o trabalho de luto como coexistência e não substituição. Assim, é um processo em que o enlutado passa por uma: “dor extrema (...) mistura de esvaziamento do eu e de contração em uma imagem-lembrança" (NASIO, 2007, p. 10), ou seja, o trabalho de luto opera na simbolização do objeto perdido, ao que Freud chama de fantasia e a que Lacan (2008) conceberá como o fantasma. Ao pensar uma lógica para o fantasma, Lacan retoma as discussões do Outro já refletidas anteriormente concebendo o fantasma para tornar mais evidente a dimensão do real que se pode perceber nas formulações simbólicas e imaginárias retomando também a pulsão de morte freudiana.

Lendo as cartas, não podemos deixar de perceber que Diego Rivera, que partiu para o México há quatro anos, é o fantasma que assola Quiela, pois o fantasma é aquele que retorna.

\footnotetext{
${ }^{7}$ No original: "Cuando perdemos algunos de estos lazos que nos constituyen, no sabemos quiénes somos ni qué hacer. En un nivel, descubro que te he perdido a "ti" sólo para descubrir que "yo" también desaparezco. En otro nivel, tal vez lo que he perdido "en" ti, eso para lo que no tengo palabras, sea una relación no constituida exclusivamente ni por mí ni por ti, pero que va a ser concebida como el lazo por el que estos términos se diferencian y se relacionan" (BUTLER, 2006, p. 48).
} 
Lacan (1985) discorre que esse fantasma é, na verdade, o eu que se elabora e se disfarça para compreender o mundo e que: "é sempre ao redor da sombra errante do seu próprio eu que vãose estruturando todos os objetos de seu mundo" (LACAN, 1985, p. 211), um eu que é desvinculado, despedaçado; e que outra forma de ser fragmentado que não pela dor da perda, que não pelo corte dos laços que nos conduzem à referência? Pensando nesse ponto, Jean Allouch (1939- ), discípulo de Lacan, retoma os textos freudianos e lacanianos e conclui que o trabalho de luto deve ser promovido ao status de ato e, ainda mais, de um ato sacrificial.

O luto não é somente perder a alguém (...), se não também convocar nesse lugar um ser fálico para poder sacrificá-lo. O luto é efetuado se e somente se houver efetivo sacrifício. O sujeito terá perdido não apenas a alguém somente, além, somente, uma parte somente, como um suplemento, um pequeno pedaço de si (ALLOUCH, 2011, p. 300 , tradução nossa). ${ }^{8}$

Allouch defende essa troca buscando na literatura, especialmente em Hamlet (1601), de William Shakespeare, arcabouços que comprovem sua teoria, bem como essa busca dialoga com os textos dos dois grandes psicanalistas Freud e Lacan. Contudo, penso que esse "pedaço de si" dialoga com o que Butler (2006) chamará de "laços" e tudo o que esses laços representam. Allouch (2011) afirma que a dor do corte vem da vitalidade que o objeto faltoso dispunha quando ainda vivo, assim, a morte de uma criança é muito mais sentida do que a morte de um ancião. Nisso, retornamos a Butler (2007) e o luto sociopolítico porque, mesmo sendo cruciante a perda de um filho, há outras perdas tão dolorosas quanto como, por exemplo, a pátria e a identidade cultural no caso dos exilados. Sendo assim, não são todos os lutos que produzem fantasmas, mas certos lutos em que a força necessária para cortar os laços, ou “pedaço de si”, é descomunal. Esse luto é compreendido por Abraham e Törok (1995), discípulos de Freud, como luto indizível.

O luto indizível instala no interior do sujeito uma sepultura secreta. Na furna repousa, vivo reconstituído a partir de lembranças, de palavras, de imagens e de afetos, o correlato objetal da perda, enquanto pessoa completa, com sua própria tópica, bem como os momentos traumáticos - efetivos ou supostos - que haviam tornado a introjeção impraticável.Criou-se, assim, todo um mundo fantasístico inconsciente que leva uma vida separada e oculta. Acontece, entretanto, que, por ocasião das realizações libidinais, "à meia-noite", o fantasma da cripta vem assombrar o guardião do cemitério, fazendo-lhes sinais estranhos e incompreensíveis, obrigando-o a realizar

\footnotetext{
${ }^{8}$ No original: "El duelo no es solamente perder a alguien (...), sino también convocar en ese lugar a un ser fálico para poder sacrificarlo. El duelo es efectuado si y sólo si se ha hecho efectivo ese sacrificio. El sujeto habrá perdido entonces no solamente a alguien sino, además, sino, aparte, sino, como suplemento, un pequeño trozo de si" (ALLOUCH, 2011, p. 300).
} 
atos insólitos, infligindo-lhe sensações inesperadas (ABRAHAM; TÖROK, 1995, p. 249).

Esses rituais podem ser percebidos na obra quando Quiela começa a pintar no cavalete que Diego Rivera pintava e que, inclusive, havia deixado um quadro pela metade. A história oficial que apagara Angelina Beloff trazendo-a como "a primeira esposa de Diego Rivera" representa essa importante mulher e artista mexicana como a "sombra" de Diego Rivera, contudo, Elena Poniatowska inverte (e talvez subverte) essa lógica e nos mostra que, na verdade, a sombra, o fantasma é Diego Rivera. Esse fantasma exige certos ritos, mas, como veremos, Quiela, através do trabalho de luto, corta esse pedaço de si e fecha a cripta que a assombra, restando desses ritos a construção de uma identidade cultural. Angelina Beloff tempos depois parte para o México, cujo céu é sempre azul e, na leitura deste trabalho, não em busca de Diego, mas para ocupar seu lugar e ratificar sua identidade.

A primeira carta data de 19 de outubro de 1921, nessa carta, Quiela avisa a Diego que tem estudado espanhol e que tem conseguido avançar muito rapidamente no idioma enviando a ele uma fotografia com dedicatória. Já destaca que a falta de Diego, seu objeto faltoso, faz com que Paris esteja também vazia. Quiela tenta seguir sua vida sem Diego, tentando conviver com o vazio e o silêncio que já invadem sua produção artística ao afirmar que: "Pela manhã, como se estivesses presente, me sento e começo a preparar as ilustrações para Floreal. Eu abandonei as formas geométricas e me vejo bem fazendo paisagens um tanto doentes e cinzas, desfoques e solitárias. Sinto também que eu poderia me apagar com facilidade" (PONIATOWSKA, 1985, p. 9, tradução nossa) ${ }^{9}$. O luto que toma conta de Quiela pode ser percebido no uso do cinza, que também toma conta do inverno parisiense, além de ser um luto profundo em que, segundo Freud, há "perda de interesse pelo mundo externo" (FREUD, 1996, p. 250), luto que se assemelha, em muito, com melancolia. Quiela encerra com "Te beija mais uma vez" (PONIATOWSKA, 1985, p. 10, tradução nossa). ${ }^{10}$

A segunda carta data de 7 de novembro de 1921 e Quiela questiona o silêncio de Diego que não lhe escreve uma única e fina linha, nem mesmo sobre os desenhos, assunto ligado a ambos. Retoma o primeiro contato de ambos sob influência da família Zeting, rememorando boas e más lembranças do inverno francês em que Dieguito contraíra pneumonia. Essa carta é

\footnotetext{
${ }^{9}$ No original: "En la mañana, como si estuvieras presente, me siento a preparar las ilustraciones para Floreal. He abandonado las formas geométricas y me encuentro bien haciendo paisajes un tanto dolientes y grises, borrosos y solitarios. Siento que también yo podría borrarme con facilidad" (PONIATOWSKA, 1985, p. 9).

${ }^{10}$ No original: “Te besa una vez más” (PONIATOWSKA, 1985, p. 10).
} 
mais extensa que a primeira e, constantemente, Quiela busca a voz ausente e a imagem de Diego, afirmando seu amor e confessando-lhe a dor de sua ausência, a angústia que sente.

Te amo Diego, agora eu sinto uma dor quase insuportável no meu peito. Na rua, foi assim que aconteceu comigo, eu fui atingida pela sua memória e não posso mais andar e algo me machuca que eu tenho que recarregar contra a parede (PONIATOWSKA, 1985 , p. 14 , tradução nossa). ${ }^{11}$

Quiela pede desculpas por ser sentimental demais, além disso, identifica-se ainda como russa, afirmando que é russa, mulher e sentimental. Esse fato a faz repensar a cena em que se encosta em um muro e nega a ajuda de transeunte francês, afirmando que os franceses não gostavam de estrangeiros. Por fim, a despedida dessa carta faz menção à primeira em que ela torna a escrever "Te encho de beijos", assinando Quiela.

A terceira carta data de 15 de novembro de 1921 e é uma das mais extensas. Nessa carta, ela descreve a ausência que a invade. Percebemos que os objetos deixados por Diego são simbolizados e tomam o lugar de sua representação, ou seja, os objetos deixados para trás rompem com a ausência de Diego que retorna na memória de Quiela. Ela começa a carta com: "Hoje como nunca te estranho e te desejo Diego, teu grande corpanzil preenchia todo o estúdio" (PONIATOWSKA, 1985, p. 15, tradução nossa) ${ }^{12}$, ela encontra um blusão que ainda mantêm as formas de Diego e se agarra a ele como forma de resgatar essa presença ausente.

Nessa terceira carta, já podemos notar que o trabalho de luto já se iniciou ao passo que Quiela compreende que: "minha esfera de silêncio que és tu, tu e o silêncio, eu adentro o silêncio, eu dentro de ti que és a ausência" (PONIATOWSKA, 1985, p. 16, tradução nossa) ${ }^{13}$, essa entrada de Quiela na ausência faz parte do processo conhecido como trabalho de luto e discorrido, em especial, por Abraham e Törok (1995) como incorporação em que o enlutado simboliza o objeto faltoso, nessa fase, em certos casos, há a presença dos sonhos do "cadáver saboroso". Ela retoma que Diego fale com ela, que lhe escreva nem que seja em nome de Dieguito. Então, retoma o processo de luto de Diego em que ele: “estavas ausente, nem uma só vez me dirigiste a palavra, nem sequer te moveste quando te peguei pelo braço"

\footnotetext{
${ }^{11}$ No original: "Te amo Diego, ahora mismo siento un dolor casi insoportable en el pecho. En la calle, así me ha sucedido, me golpea tu recuerdo y ya no puedo caminar y algo me duele que tengo que recargarme contra la pared" (PONIATOWSKA, 1985, p. 14).

${ }^{12}$ No original: "Hoy como nunca te extraño y te deseo Diego, tu gran corpachón llenaba todo el estudio" (PONIATOWSKA, 1985, p. 15).

${ }^{13}$ No original: "mi esfera de silencio que eres tú, tú y el silencio, yo adentro del silencio, yo dentro de ti que eres la ausencia" (PONIATOWSKA, 1985, p. 16).
} 
(PONIATOWSKA, 1985, p. 18, tradução nossa) ${ }^{14}$. Diego passa pelo mesmo luto indizível, com a morte do filho, que Quiela passa com a sua morte mesmo que simbólica. Ela encerra a carta com os "beijos" e lembrando de seu amor, dessa vez assina apenas como "Quiela".

A quarta carta é datada de 2 de dezembro de 1921 e é uma carta bem mais curta que a anterior. Nela, Quiela retoma o apelido de Diego de "chatito", maneira como Diego era chamado pelos seus pais. Ela conta nessa carta sua visita, dessa voz sozinha, ao Museu do Louvre e retoma as lembranças de quando eles iam até lá juntos. Após o passeio, ela retorna eufórica, com vontade de pintar e, então, retira o quadro de Diego inacabado que permanecia intacto no cavalete. "Pela primeira vez ao longo desses quatros longos anos sinto que estás longe, estou cheia de ti, quero dizer de pintura" (PONIATOWSKA, 1985, p. 21, tradução nossa). ${ }^{15}$ Talvez, essa passagem marque o ponto em que Quiela perceba que Diego não mais retornará, visto sua constante e gritante ausência. Ela encerra ainda com a esperança de que ele consiga perceber, com sua sensibilidade, a comoção de quem ainda o ama e que assina como "sempre tua".

A quinta carta data de 17 de dezembro, 15 dias após a quarta carta. Esta carta é mais extensa que a anterior e nela Quiela desculpa-se pela demora em escrever por ter sido acometida por uma febre ainda relacionada à sua eufórica visita ao Louvre. Percebemos nesta carta que, segundo Abraham e Törok (1995), era meia-noite e o fantasma de Diego exigia certos ritos: pintar. "Me levantei às quatro da manhã, como tu fazias e tratei de organizar a composição e segui fazendo-o todo o dia, lutei como nem imaginas, nem sequer me levantei para cozinhar" (PONIATOWSKA, 1985, p. 22, tradução nossa). ${ }^{16}$ Além de acordar no mesmo horário em que Diego costumava acordar, Quiela conta que abrira a janela de forma inconsciente como Diego fazia. Nessa carta, também, percebemos o que Allouch (2011) chama de evocar um "ser fálico", um pedaço de si para ser sacrificado.

Pensei que seu espírito tinha tomado posse de mim, que era você e não eu que estava dentro de mim, que esse desejo febril de pintar veio de você e eu não queria perder um segundo de sua posse. Eu me transformei em gorda Diego, eu transbordei, eu não me encaixava no estúdio, eu era alta como você, ia contra os espíritos - uma vez você me disse que você tinha relações com o diabo e eu me lembrei naquele momento porque minha caixa torácica se expandiu de uma forma que os peitos incharam, as

\footnotetext{
${ }^{14}$ No original: "estabas ausente, ni una sola vez me dirigiste la palabra, ni siquiera te moviste cuando te tomé del brazo" (PONIATOWSKA, 1985, p. 18).

${ }^{15}$ No original: "Por primera vez a lo largo de estos cuatros largos años siento que no estás lejos, estoy llena de ti, es decir de pintura" (PONIATOWSKA, 1985, p. 21).

${ }^{16}$ No original: "Me levanté a las cuatro de la mañana como tú lo hacia y traté de organizar la composición y seguí haciéndolo todo el día, luché como no te imaginas, ni siquiera me levanté para cocinar" (PONIATOWSKA, 1985, p. 22).
} 
bochechas, a papadas; era eu um único pneu, busquei o espelho e sem efeito, ali estava minha cara inchada e larga, latejando como se tivessem soprado com um fole de dentro (PONIATOWSKA, 1985, p. 23, tradução nossa). ${ }^{17}$

Esse é o ápice da presença ausente do fantasma que ronda Quiela. Essa presença está dentro dela; é parte dela e, ao mesmo tempo, parte de Diego Rivera e, ao mesmo tempo, de nenhum dos dois, é o que Allouch (2011) chama de um pedaço de si. Quiela ainda rememora a ausência de outro objeto faltoso: a morte de Dieguito. Apesar da saudade e da dor que sente da morte do filho, Quiela demonstra que seu trabalho de luto fora encerrado ao afirmar que Dieguito: "está morto e eu não lhe faço falta em nada" (PONIATOWSKA, 1985, p. 26, tradução nossa $)^{18}$. Encerra com “tristemente" e começa a assinar como “Tua Quiela”, que se repetirá nas cartas que se sucedem a esta.

A sexta carta data de 23 de dezembro de 1921 e conta com um pós-escrito. Quiela começa contando que fora chamada, outra vez, para produzir trabalhos para a revista Floreal, retornando da revista encontra-se com Monsieur Vicent que se assusta com a palidez cadavérica de Quiela. Como em outras cartas, ela rememora os trabalhos artísticos feitos em conjunto com Diego Rivera, o que nos faz lembrar que há muito de Angelina Beloff na formação artística de Diego e, se ele é considerado esse gênio, a ela também é preciso delegar essa genialidade e essa sensibilidade artística. Mas retornando à leitura enlutada, percebemos que ela passa por um período em que a imagem do objeto faltoso lhe toma a vitalidade.

Quiela ainda recorda de seu fantasma nesse processo lento e constante de reorganização das energias psíquicas como afirma Nasio (2007). Ela reflete na carta:

Me fazes falta, chatito, eu levanto meu esboço no ar e mostro a você, me pergunto se
você come bem, quem serve você, se você continua fazendo essas jornadas de trabalho
exaustivo, se suas explosões de cólera diminuíram, uma grande, produtiva, raiva
criativa que você se arrastou como um rio, você transbordou, você se desfez e ainda
estávamos imersos na cachoeira, eu lhe pergunto se você só vive para pintar como
você fez aqui em Paris, se você ama uma nova mulher, o curso que você tomou
(PONIATOWSKA, 1985, p. $31-32$, tradução nossa). ${ }^{19}$

${ }^{17}$ No original: "Pensé que tu espíritu se había posesionado de mi, que eras tú y no yo el que estaba dentro de mí, que este deseo febril de pintar provenía de ti y no quise perder un segundo de tu posesión. Me volví hasta gorda Diego, me desbordaba, no cabía en el estudio, era alta como tú, combatía en contra de los espíritus- tú me dijiste alguna vez que tenías tratos con el diablo- y lo recorde en ese momento porque mi caja toráxica se espandió a tal grado que los pechos se me hincharon, los cachetes, la papada; era yo una sola llanta, busque un espejo y en efecto, allí estaba mi cara abotagada y ancha, palpitante como si la soplaran con un fuelle desde adentro" (PONIATOWSKA, 1985, p. 23).

${ }^{18}$ No original: "está muerto y yo no le hago falta a nadie" (PONIATOWSKA, 1985, p. 26).

${ }^{19}$ No original: "Me haces falta, chatito, levanto en el aire mi boceto y te lo muestro, me pregunto si comerás bien, quién te atiende, si sigues haciendo esas exhaustivas jornadas de trabajo, si tus explosiones de cólera han disminuido, una cólera genial, productiva, creadora en que te arrastabas a ti mismo como un rio, te revolvias desbordante, te despeñabas y nosotros te seguíamos inmersos en la catarata, te pregunto si sólo vives para la pintura 
Esse ponto da carta marca, além de um questionamento a Diego, uma autorreflexão em que Quiela pergunta também a ela mesma. Aqui conhecemos um pouco mais da relação estabelecida entre Diego e ela, bem como a produção criativa do artista que criava exaustivamente sob a influência dos ataques de cóleras. Esses "ataques" foram os mesmos que assolaram Quiela e que a fizeram pintar e desenhar exaustivamente e que, como consequência, levaram-na a ter a febre que desencadeou e exteriorizou o pedaço de si que a rondava como fantasma. Quiela se despede, mais uma vez, como "Tua Quiela" e escreve o P.S. (pós-escrito) que enviará a Diego sua produção feita para a revista.

A sétima carta data de 29 de dezembro de 1921, em torno de uma semana após a sexta, é uma das mais extensas de Quiela, a última de 1921, que começa refletindo sobre as excessivas horas de trabalho pintando. Essa carta vai destacar todo o processo artístico de Quiela e a composição de seu traço artístico. Deste traço, ela percebe que começa a representar artisticamente crianças em sua inocência. A carta encerra com: "Te abraço e te digo novamente que te amo, te amarei sempre, passe o que passar" (PONIATOWSKA, 1985, p. 40, tradução nossa $)^{20}$, assinando como “Tua Quiela”.

A oitava carta é a primeira de 1922, datada de 2 de janeiro de 1922. Nessa carta, Quiela faz sua autorreflexão acerca de escritos encontrados e, percebendo-se já outra pessoa, mesmo ainda em processo, passa por um processo a que Freud (1996) chamará de unheimlich, traduzido para o português como "estranho", que consiste na desfamiliaridade, algo que é reconhecidamente meu, mas que, ao mesmo tempo, não percebo como meu. "Nos papéis que estão os esboços habituais, escrevi com uma letra que não reconheço" (PONIATOWSKA, 1985, p. 41, tradução nossa) ${ }^{21}$, ou seja, os escritos foram rabiscados por Quiela, mas no começo de seu trabalho de luto e, logo aqui já evocada a presença do ausente, ela não os reconhece mais.

Os bilhetes operam como uma espécie de diário de espera, em que ela marca os horários em que escreve e demarca a ausência de Diego. Essa espera, esse aguardar insistentemente, já não faz parte de Quiela, ela, a cada dia que passa, compreende que Diego não vai retornar. “As últimas palavras estão escritas com violência, quase rasgam o papel e choro diante da

como lo hiciste aquí en Paris, si amas a una nueva mujer, qué rumbo has tomado"(PONIATOWSKA, 1985, p. 31$32)$.

${ }^{20}$ No original: "Te abrazo y te digo de nuevo que te amo, te amaré siempre, pase lo que pase" (PONIATOWSKA, 1985, p. 40).

${ }^{21}$ No original: "En los papeles que están los bocetos habituales, he escrito con una letra que no reconozco" (PONIATOWSKA, 1985, p. 41). 
puerilidade de meu alívio" (PONIATOWSKA, 1985, p. 42, tradução nossa) ${ }^{22}$. Essa violência e essa raiva fazem parte do trabalho de luto, marcada nessa necessidade de ruptura, de exteriorizar a dor. Quiela ainda reflete que: "Quanto a mim, posso afirmar que a dor de dentes seguirá que até que apodreça a raiz" (PONIATOWSKA, 1985, p. 42, tradução nossa) ${ }^{23}$, ou seja, é um trabalho de escavar, de retirar fundo e, por isso, é um processo lento.

Nessa autorreflexão, que Quiela faz sobre o seu trabalho de luto, surgem questionamentos acerca desse silêncio constante de Diego que o máximo que lhe relega é o envio mensal de remessas de dinheiro. Nessa reflexão, Diego retorna, afinal é essa a figura do fantasma: “Ainda te vejo com seus sapatos deformados, teu velho chapéu escuro, tuas calças ásperas, tua estatura monumental, tua barriga sempre precedendo você e acho que absolutamente ninguém poderia usar roupas tão desgastadas" (PONIATOWSKA, 1985, p. 44, tradução nossa) ${ }^{24}$. Diego, ainda, é o fantasma que retorna para assombrar Quiela, isso marca o quanto o trabalho de luto ainda não se encerrou, mas, podemos perceber, que se encaminha para seu desfecho.

Além disso, ainda na oitava carta, percebemos que a dor dessa perda não está relacionada somente à figura de Diego, mas aos laços que prendem Quiela ao artista plástico respeitado e de sucesso. Esses laços também são a construção de uma identidade cultural que Angelina Beloff desenvolverá assim que chega ao México. Quiela afirma a Diego: "me mexicanei terrivelmente e sinto-me ligada par procuration ao teu idioma, à tua pátria, a milhões de pequenas coisas" (PONIATOWSKA, 1985, p. 46, tradução nossa) ${ }^{25}$. Ou seja, Diego representa o México, o céu sempre azul do México e, talvez, seja esse o laço mais difícil de ser cortado. Mas Quiela já compreende que Diego não mais retornará encerrando a carta com: "Meu querido Diego te abraço fortemente, desesperadamente por sobre o oceano que nos separa" (PONIATOWSKA, 1985, p. 49, tradução nossa) ${ }^{26}$, e assina outra vez "Tua Quiela".

A nona carta data de 17 de janeiro de 1922, 15 dias após a oitava e, diferente da anterior, é mais curta. Quiela já começa a carta demonstrando certa independência da opinião de Diego: "Não tens me mandado falar nada dos esboços, assim sendo sigo sozinha porque Floreal não

\footnotetext{
${ }^{22}$ No original: "Las últimas palabras están trazadas con violencia, casi rompen el papel y lloro ante la puerilidad de mi desahogo" (PONIATOWSKA, 1985, p. 42).

${ }^{23}$ No original: "En cuanto a mí, puedo afirmar que el dolor de muelas seguirá hasta que se pudra la raíz" (PONIATOWSKA, 1985, p. 42).

${ }^{24}$ No original: "Aún te veo con tus zapatos sin bolear, tu viejo sombrero olanudo, tus pantalones arrugados, tu estatura monumental, tu vientre siempre precediéndote y pienso que nadie absolutamente, podría llevar con tanto señorío prendas tan ajadas" (PONIATOWSKA, 1985, p. 44).

${ }^{25}$ No original: "me mexicanicé terriblemente y me siento ligada par procuration a tu idioma, a tu patria, a miles de pequeñas cosas" (PONIATOWSKA, 1985, p. 46).

${ }^{26}$ No original: Mi querido Diego te abrazo fuertemente, desesperadamente por encima del océano que nos separa" (PONIATOWSKA, 1985, p. 49).
} 
pode esperar" (PONIATOWSKA, 1985, p. 50, tradução nossa) ${ }^{27}$, marcação de que o trabalho de luto se encaminha ao seu fim. Nessa carta, também, outro fantasma que retorna, já superado, toma conta das produções de Quiela: Dieguito. Quiela, também, conta a visita de Zadkin que a questiona sobre a venda do ateliê: "Eu o repreendi que não, que eles eram minha própria vida, que ao ir para o México eles seriam minha única bagagem" (PONIATOWSKA, 1985, p. 52, tradução nossa) ${ }^{28}$. A carta encerra-se com um abraço de toda alma de Quiela e a assinatura segue o padrão das anteriores com "Tua Quiela".

A décima carta data de 28 de janeiro de 1922, 11 dias após a nona e marca um novo ciclo de questionamentos a Diego que permanece em seu silêncio aterrador, Quiela o questiona sobre Marievna Vorobiev Stebelska e a filha que ela tem com Diego, a pequena Marika. Aqui a dor não está no fato de ele também enviar remessas de dinheiro a outra mulher na França, mas a negação de Diego em ter outro filho com Quiela após a morte de Dieguito, a dor se pauta em Marika viva e seu Dieguito morto. Ela não condena a atitude de Diego, ao contrário, consideraa nobre, afinal, a pequena Marika necessita desta ajuda, mas questiona, outra vez, o silêncio em torno de tantas possibilidades de contato.

A décima carta traz dois pontos importantes para o último ciclo do trabalho de luto. A primeira mudança ocorre nas produções artísticas de Quiela que, na primeira carta, traziam cores cinza e paisagens enlutadas. "Quisera encontrá-lo porque justamente pintei uma paisagem de água e gostaria de relembrar algo daquela praia" (PONIATOWSKA, 1985, p. 58, tradução nossa ${ }^{29}$, ou seja, o luto que assolava Quiela em 1921 já não mais a perturba, permitindo-lhe que pinte outras figuras que não apenas as cinzas. Ela ainda encerra: “Avanço lentamente, estou muito longe de pintar como o pássaro canta, como nos exige Renoir, porém eu sou o seu pássaro, depois de tudo, e aninhado para sempre em suas mãos" (PONIATOWSKA, 1985, p. 58 , tradução nossa $)^{30}$. Apesar de afirmar que está longe de pintar como canta o pássaro, essa figura que representa, simbolicamente, a liberdade marca esse fim de um trabalho de luto que fora, sobretudo, doloroso e acentuado pelo silêncio do objeto faltoso, silêncio esse que marca, realmente, a morte de Diego Rivera.

\footnotetext{
${ }^{27}$ No original: "No me has mandado decir nada de los bocetos, así es que me lanzo sola porque Floreal no puede esperar" (PONIATOWSKA, 1985, p. 50).

${ }^{28}$ No original: "Le repuse que no, que eran mi vida misma, que de irme a México serían mi único equipaje" (PONIATOWSKA, 1985, p. 52).

${ }^{29}$ No original: "Quisiera encontrarlo porque justamente pinté un paisaje de agua y me gustaría recobrar algo de aquella playa” (PONIATOWSKA, 1985, p. 58).

${ }^{30}$ No original: “Avanzo lentamente, estoy muy lejos de pintar como el pájaro canta, como lo pedía Renoir, Pero soy tu pájaro al fin y al cabo y anidado para siempre entre tus manos” (PONIATOWSKA, 1985, p. 58).
} 
A décima primeira carta, penúltima, é datada de 2 de fevereiro de 1922 e, como fantasma, Quiela se alegra com o recebimento de uma carta timbrada do México, contudo não era de Diego, e sim de seu pai que estivera doente: "Dói-me muito saber que foi muito ruim e é verdade a minha aflição em não ser capaz de vê-lo, mas sobre o meu desejo de vê-los eu não vou mais falar com você Diego, porque a iniciativa tem que vir de você e se não..."(PONIATOWSKA, 1985 , p. 59, tradução nossa) ${ }^{31}$, nesse trecho percebemos o fim do luto, o momento em que Quiela diz chega, não terás mais meus questionamentos, se tu és silêncio eu também serei. Retomo, então, Butler (2006) ao afirmar que: “um luto se elabora quando se aceita que devemos suplantar a causa da perda sofrida, provavelmente, para sempre” (BUTLER, 2006, p. 47, tradução nossa) ${ }^{32}$.

Essa carta também constitui uma das mais extensas, Quiela retoma vários questionamentos como, por exemplo, a negação de Diego a ter outro filho com ela após a morte de Dieguito, entre outros já feitos em cartas anteriores. Repete, mais uma vez, a frase que Diego pintava o México para ela: “Aqui todos os rostos são claros sobre fundos mais escuros. Em meu país são rostos escuros sobre fundos claros" (PONIATOWSKA, 1985, p. 63, tradução nossa) ${ }^{33}$. Ainda, percebemos a troca do tempo verbal flexionado nas primeiras cartas no presente do indicativo e nesta, em especial, flexionados no pretérito perfeito ao afirmar que: "Todo o mundo se interessava por ti” (PONIATOWSKA, 1985, p. 67, tradução nossa) ${ }^{34}$, marcando esse fim, esse passado. Quiela encerra a carta mostrando o rastro do corte dos laços, a ferida já fechada, mas ainda presente: "Sigo sendo teu pássaro azul, sigo sendo simplesmente azul como costumava chamar-me, eu inclino minha cabeça, minha cabeça ferida definitivamente e a coloco em teu ombro e te beijo o pescoço, Diego, Diego, Diego a quem tanto amo." (PONIATOWSKA, 1985, p. 68, tradução nossa) ${ }^{35}$, assina, pela última vez, "Tua Quiela", encerrando o ciclo do trabalho de luto.

A décima segunda carta, a última, é escrita passados 5 meses da penúltima carta, um lapso temporal em que Quiela abre a carta discorrendo sobre ele. O único motivo para escrever é o

\footnotetext{
${ }^{31}$ No original: "Me duele mucho saber que estuvo muy malo y es verdadera mi aflicción al no poderlo ver, pero acerca de mi deseo de verlos ya no te hablaré más Diego, porque la iniciativa tiene que venir de ti y si no..." (PONIATOWSKA, 1985, p. 59).

${ }^{32}$ No original: "un duelo se elabora cuando se acépta que vamos a cambiar a causa de la pérdida sufrida, probablemente para siempre" (BUTLER, 2006, p. 47).

${ }^{33}$ No original: "Aquí todos son rostros claros sobre fondos más oscuros. En mi país son rostros oscuros sobre fondos claros" (PONIATOWSKA, 1985, p. 63).

${ }^{34}$ No original: "Todo el mundo se interesaba en ti" (PONIATOWSKA, 1985, p. 67).

${ }^{35}$ No original: "Sigo siendo tu pájaro azul, sigo siendo simplemente azul como solías llamarme, ladeo la cabeza, mi cabeza herida definitivamente y la pongo sobre tu hombro y te beso el cuello, Diego, Diego, Diego a quién tanto amo" (PONIATOWSKA, 1985, p. 68).
} 
de agradecer o dinheiro enviado por Diego a ela e, mesmo assim, questionar seu silêncio. $\mathrm{O}$ corte, o sacrifício de um "pedaço de si” ocorre quando Quiela descobre, em definitivo, que Diego possui um "amor mexicano". "Você vê que eu estou bem ciente, não porque eu tento descobrir, mas porque seus e meus amigos dizem de golpe e baque, sem dúvida, porque eles pensam que estão me fazendo bem por me tirar do sonho em que vivo" (PONIATOWSKA, 1985, p. 70, tradução nossa) ${ }^{36}$. Ela compreende o sacrifício, a necessidade do corte certeiro que a acorda do sonho azul. Encerra essa carta com abraços de afeto e assina Quiela. Ainda, escreve no P.S. a opinião de Diego sobre o seu trabalho artístico.

\title{
Considerações finais
}

Preciso marcar que esse trabalho foi financiado pela Coordenação de Aperfeiçoamento de Pessoal de Nível Superior (CAPES). Querido Diego, te abraza Quiela (1985) é publicado por Elena Poniatowska, mas a escrita, visivelmente, não pertence a ela e sim a Quiela, apelido carinhoso de Angelina Beloff. As cartas reproduzem um pequeno espaço de tempo da vida de Beloff, uma biografia ficcional ou bioficção, que retoma, em especial, o processo freudiano de trabalho de luto. Para tanto, Freud, Lacan e seus discípulos nos servem de base para essa leitura enlutada em que percebemos o corte, o sacrifício de um pedaço de si (ALLOUCH, 2011) ou dos laços (BUTLER, 2006) que ligam Diego Rivera e Angelina Beloff. O fato de ser conhecida sob o epíteto de "primeira esposa de Diego" contribui para o seu apagamento e o seu silenciamento, ao ponto que a biógrafa Poniatowska silencia Diego, permitindo que a voz sufocada de Quiela tome a pena e conte ela mesma esse pedaço de sua história. Mas, afinal, o que é esse processo de luto? Quem questiona e responde é Juan-David Nasio (2007).

\begin{abstract}
O que é então o luto? É preservar vivo o morto, ao mesmo tempo reconhecendo que ele não é mais do nosso mundo. Essa constatação, esse trabalho, não se faz num instante, é preciso tempo, eis por que isso se chama trabalho de luto. É preciso tempo e é preciso trabalho. O que é o trabalho? É dizer todos os dias "ele não está aqui", e também "ele está dentro de mim". É o ritual que ajuda. O ritual não passa de uma maneira de garantir que ele está dentro de mim e que não está aqui. O ritual de ir ao cemitério, o ritual de pensar nele, o ritual de uma palavra, todos os rituais simbólicos relativos à morte de um ente são maneiras que o sujeito utiliza para dizer: ele não está aqui e está dentro de mim (NASIO, 2007, p. 71).
\end{abstract}

\footnotetext{
${ }^{36}$ No original: "Ya ves que estoy bien enterada, no porque intente averiguarlo sino porque tus amigos y los míos me lo dicen de golpe y porrazo sin duda alguna porque creen hacerme un bien al sacarme del sueño en el que vivo" (PONIATOWSKA, 1985, p. 70).
} 
Essa afirmação de Nasio dialoga com a concepção lacaniana $(1985 ; 2005)$ de fantasma, e freudiana (1996) de fantasia, bem como com o conceito ferencziano de introjeção (ABRAHAM; TÖROK, 1995). Quiela passa por esse processo, doloroso demais, cortando os laços que a referenciam, ainda historicamente, como esposa de Diego Rivera, mas retomando Freud: "quando o trabalho de luto se conclui, o ego fica outra vez livre e desinibido" (FREUD, 1986, p. 251) e Quiela encontra nas asas do pássaro azul sua liberdade inscrita sob o signo de uma nova identidade cultural. Como afirma Guerrero Olavarriete: “Angelina Beloff (...) se entregou ao México" (GUERRERO OLAVARRIETA, 2017, p. 186, tradução nossa) ${ }^{37}$.

\section{Referências}

ABRAHAM, Nicolas; TÖROK, Maria. A casca e o núcleo. Trad. Maria José R. Faria Coracini. São Paulo: Escuta, 1995.

ALLOUCH, Jean. Erótica del duelo en tiempos de la muerte seca. Trad. Silvio Mattoni. Buenos Aires: El cuenco de plata, 2011.

BARTHES, Roland. Sade, Fourier, Loyola. Rio de Janeiro: Martins Fontes, 1979.

BOLAÑOS, Aimée González. Ofício de lectora. Rio Grande: Ed. FURG, 2016.

BUTLER, Judith. Vida precária: El poder del duelo y la violencia. Buenos Aires: Paidós, 2006.

FREUD, Sigmund. Luto e melancolia. In: Obras psicológicas completas de

Sigmund Freud. Trad. Jayme Salomão. V. 14. Rio de Janeiro: Imago, 1996.

FREUD, Sigmund. O estranho. In: . Obras psicológicas completas de Sigmund

Freud. Trad. Jayme Salomão. V. 17. Rio de Janeiro: Imago, 1996.

GUERRERO OLAVARRIETA, Ana Paula. Angelina Beloff como misionera cultural: una revolución de su arte. Monograma. Revista Iberoamericana de Cultura y Pensamiento, n. 1, p. 177-193, 2017.

LACAN, Jacques. O eu na teoria de Freud e na técnica da psicanálise (1954-1955). Trad. Marie Christine Lasnik Penot e Antonio Luiz Quinet de Andrade. Rio de Janeiro: Jorge Zahar, 1985.

LACAN, Jacques. A lógica do fantasma. Seminário 1966-1967. Trad. Letícia Fonseca. Recife: Centro de Estudos Freudianos do Recife, 2008.

\footnotetext{
${ }^{37}$ No original: “Angelina Beloff (...) se entregó a México” (GUERRERO OLAVARRIETA, 2017, p. 186). 
NASIO, Juan-Davi. A dor de amar. Trad. André Telles e Lucy Magalhães. Rio de Janeiro: Jorge Zahar, 2007.

PONIATOWSKA, Elena. Querido Diego, te abraza Quiela. México: Biblioteca Era, 1985.

Recebido em: 03/05/2019

Aceito para publicação em: 30/11/2019 